\title{
Tribological effects of polymer surface modification through plastic deformation
}

\author{
K O LOW* and K J WONG ${ }^{\dagger}$ \\ Faculty of Engineering and Technology, Multimedia University, 75450 Melaka, Malaysia \\ ${ }^{\dagger}$ Faculty of Mechanical Engineering, Universiti Teknologi Malaysia, 81310 Skudai, Johor, Malaysia
}

MS received 8 January 2010; revised 7 April 2011

\begin{abstract}
The efficacy of using polymers in cylindrical applications depends closely on its surface friction and wear characteristics. In this regard, a surface modification technique through plastic deformation has been implemented. Roller burnishing is commonly used to improve the surface quality of non-ferrous surfaces, but no work showed concern about roller burnishing as a polymer surface treatment process. The objective of the present work is to investigate the influence of burnishing force and burnishing speed on the friction and wear performance of acetal homopolymer and polyurethane under dry and lubricated sliding conditions. The results reveal that the coefficient of friction and wear rate decreased to a minimum value and then increased as higher burnishing force and speed were applied. It was shown that roller burnishing had favourable prospective to be utilized as a valuable polymer surface treatment technique.
\end{abstract}

Keywords. Roller burnishing; acetal homopolymer; polyurethane; coefficient of friction; wear rate.

\section{Introduction}

Roller burnishing process is a chipless post machining operation traditionally used to improve the surface qualities of non-ferrous components by removing scratches, tool marks, pits and porosity (Hassan and Al-Bsharat, 1996, 1997). In this process, surface of the workpiece is compressed by the application of a highly polished and hardened roller subjected to external force. When the applied pressure exceeds the yield strength of the material, the asperities displace permanently into the valleys resulting in a smooth and uniform surface. Roller burnishing distinguishes itself from other post machining operations as it is capable of enhancing the mechanical properties of the surfaces as well. Previous works reported that roller burnishing imparts an increase in the hardness, tensile strength and yield strength, as well as generating compressive residual stresses in the surface region which could mitigate fatigue cracks (Hassan and Al-Bsharat 1996, 1997; Zhuang and Halford 2001; El-Axir and El-Khabeery 2003; Prevéy and Cammett 2004). In addition, roller burnishing also improves the surface roundness and dimension stability, which play a vital role in the fit and tolerance of assembled parts (El-Axir and El-Khabeery 2003).

With the current impetus of polymers being extensively used to substitute metallic and non-ferrous

*Author for correspondence (kolow@mmu.edu.my) components due to their excellent properties (Alauddin et al 1995), tribological characteristic is an important aspect when polymers are used in components such as bearings, gears and cams. An alleviation in energy dissipation (friction) and surface damage (wear) could translate to an improvement in accuracy, reliability and service life of the mechanical systems. Current polymer surface treatment technique includes grinding, particle beam irradiation and plasma treatments (Alauddin et al 1995; Caiazzo et al 1996; Dong and Bell 1999; Hu and Zhang 2004), with no work showing any concern about roller burnishing of polymers. However, there is a strong possibility that roller burnishing process can be used to improve the friction and wear characteristics of polymeric surfaces since they can be machined and treated mechanically. Previous researches (Hassan and Al-Bsharat 1996, 1997; Zhuang and Halford, 2001; El-Axir and ElKhabeery 2003) on non-ferrous materials indicated that different burnishing parameters like force, speed, feed rate, number of tool passes, roller dimensions, etc may yield different results, therefore, selection of the burnishing parameters for polymers is crucial. El-Tayeb et al (2008) investigated the effect of roller burnishing process and reported that the surface roughness of POM$\mathrm{H}$ and PU was decreased by $32-37 \%$ and $28-32 \%$, respectively. The main objective of the present paper was to focus on the effect of burnishing force and burnishing speed on the friction and wear characteristics of polymers. 

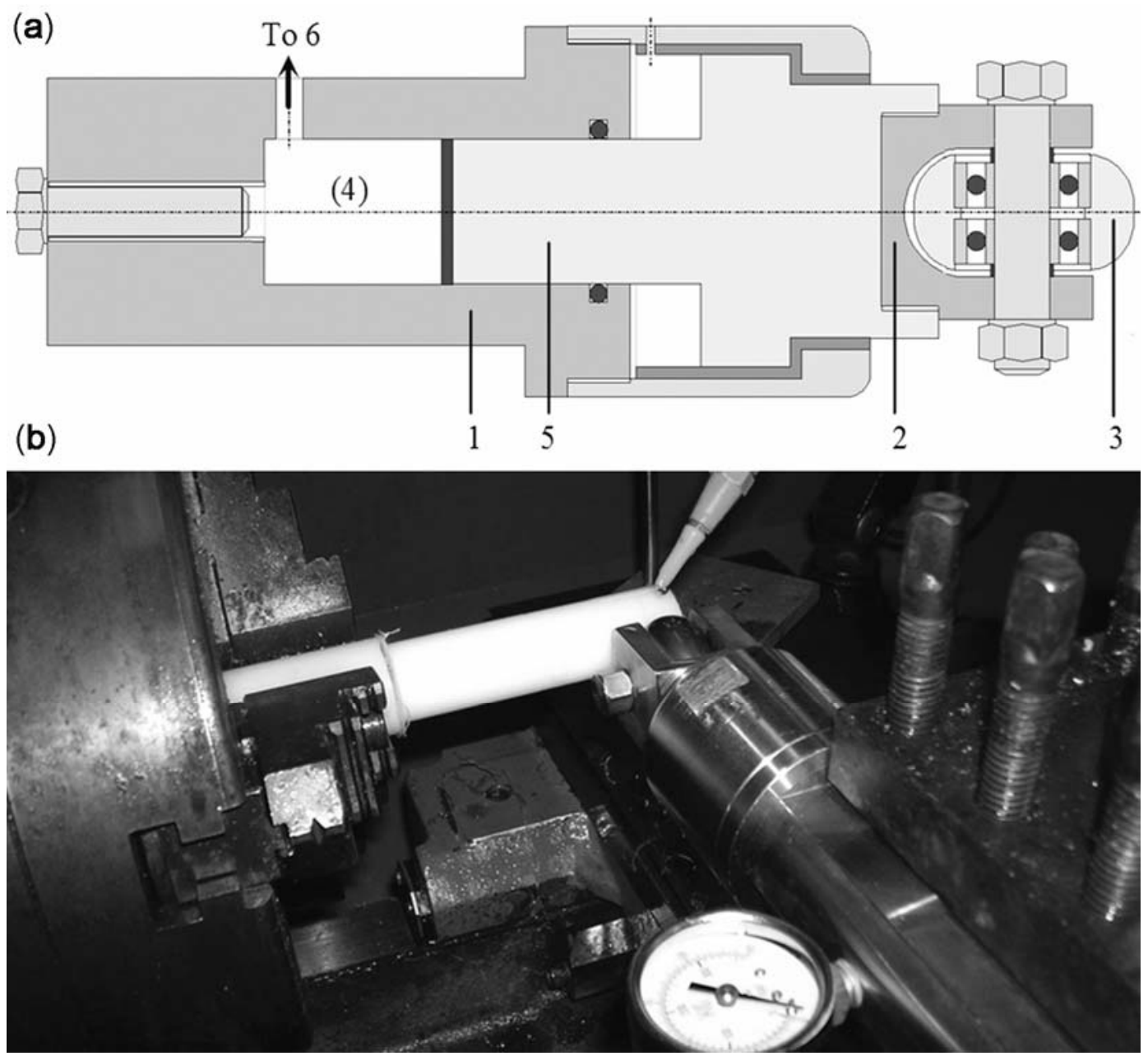

Figure 1. (a) Schematic view of roller burnishing tool (1. shank; 2. roller adapter; 3. burnishing roller; 4. hydraulic chamber (pressure); 5. guide rod; 6. pressure gauge) and (b) photograph showing roller burnishing process.

Table 1. Details of selected materials.

\begin{tabular}{lll}
\hline Properties & \multicolumn{1}{c}{ POM-H } & \multicolumn{1}{c}{ PU } \\
\hline Scientific name & Poly(oxymethylene) & Polyurethane \\
Trade name & Delrinß & Tufset \\
Tensile strength & $70 \mathrm{MPa}$ & $25 \mathrm{MPa}$ \\
Flexural strength & $90 \mathrm{MPa}$ & $65 \mathrm{MPa}$ \\
Specific gravity & $1.42 \mathrm{~g} / \mathrm{cm}^{3}$ & $1.20 \mathrm{~g} / \mathrm{cm}^{3}$ \\
Melting point & $175^{\circ} \mathrm{C}$ & NA \\
Modulus of elasticity & $3 \cdot 3 \mathrm{GPa}$ & NA \\
Water absorption & $0.9 \%$ & $0 \cdot 13 \%$ \\
Service temperature & $-50^{\circ} \mathrm{C}-100^{\circ} \mathrm{C}$ & -100 to $100^{\circ} \mathrm{C}$ \\
\hline
\end{tabular}

\section{Experimental}

\subsection{Materials specification and specimens preparation}

The polymers used were commercially available acetal homopolymer, POM-H (thermoplastic) and polyurethane, PU (thermoset) supplied by TNG Ltd., Malaysia. The properties of the materials are specified in table 1 . The selection of polymers was based on their importance in industrial applications. For instance, POM-H has excellent mechanical and machining properties and is widely used in bearings, precision gears, rollers and transport conveyors, while the low friction and high abrasion resistance characteristics of PU render it favourable for bearings, 
guides and bushing. The polymers were received in cylindrical rods and were initially turned into circular discs of $25 \mathrm{~mm}$ diameter. Roller burnishing operations were performed using specially designed burnishing tool attached on a LA430 lathe machine (figure 1). The tool consisted of a highly polished and hardened carbon chromium roller, which was fed parallel to the axis of the rotating workpiece and it rotated due to the frictional engagement between the contacting bodies. Burnishing force was applied onto the surface using hydraulic pressure and the corresponding axial sliding motion of the guide rod was detected by a pressure gauge. The variables chosen in this study were the burnishing force, $F$ (60 to $360 \mathrm{~N})$ and the spindle or burnishing speed, $n$ (110 $490 \mathrm{rpm}$ ). Single pass burnishing with $0.087 \mathrm{~mm} / \mathrm{rev}$ feed were used throughout the burnishing process.

\subsection{Friction and wear tests}

After burnishing, the burnished specimens were removed from the lathe machine and attached to a laboratory-built tribo-test machine (figure 2) for friction and wear tests. The specimen was clamped into a holder in such a way that the burnished direction was either in parallel or crossed orientation of sliding ( $\mathrm{PB}-\mathrm{O}$ or $\mathrm{CB}-\mathrm{O})$ as shown in figure 3 . The specimen was loaded normally with $20 \mathrm{~N}$ weights through a loading lever. During the test, friction forces at the sliding interface were detected using a load cell arrangement mounted on the loading lever. The loading lever was balanced by a balancing weight to ensure no initial normal load was present. A $60 \mathrm{~mm}$ diameter stainless steel counterface cup was used throughout the test. It was regularly refreshed using an abrasive paper

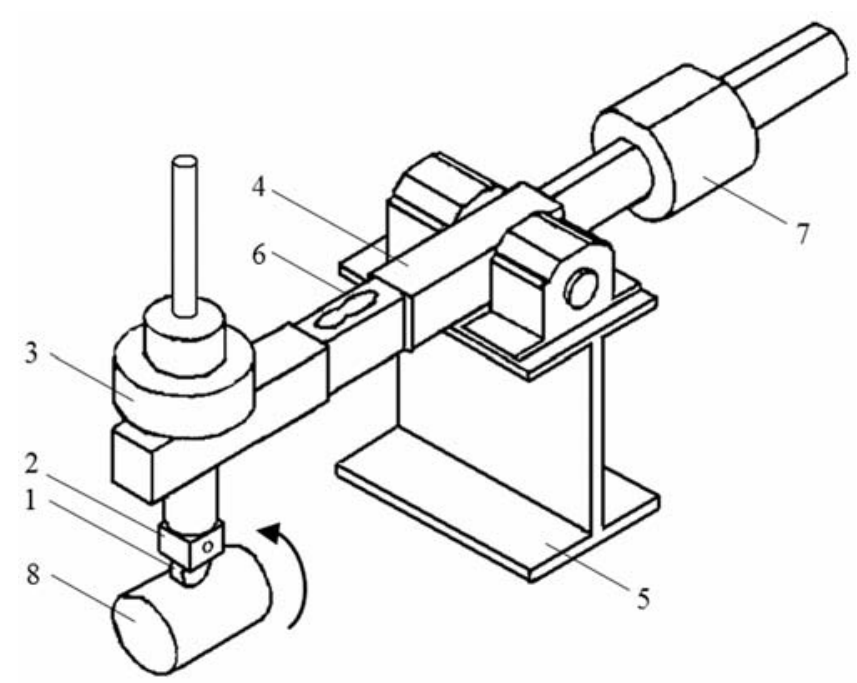

Figure 2. Schematic diagram showing the tribo-test machine (1. specimen; 2. specimen holder; 3. dead weight; 4. loading lever; 5 . frame; 6 . load cell; 7. balancing weight; 8 . counterface cup). (silicon carbide coated 600 grade) to an average roughness of $0.26 \mu \mathrm{m}$ before each test. A light viscosity lubricant (SAE 20W/40) was used when tested under lubricated contact condition. Weight loss measurements were taken using an analytical balance of $0.1 \mathrm{mg}$ resolution (Shimadzu AW220) after a running-in period of $180 \mathrm{~s}$ at a constant rotational speed of $200 \mathrm{rpm}$ (which is equivalent to a sliding velocity of $0.6283 \mathrm{~ms}^{-1}$ and a sliding distance of $0.113 \mathrm{~km})$. The specific wear rates $\left(\mathrm{mm}^{3} / \mathrm{Nm}\right)$ were deduced from the mass loss, and the inverse of specific wear rate is generally referred to as wear resistance. Figure 4 presents the coefficient of friction and specific wear rate for turned surfaces (unburnished) under various conditions. Microscopic studies of the surfaces were carried out using a scanning electron microscope (JEOL JSM840A). Each specimen had to be gold coated before SEM investigation to enhance its conductivity.

\section{Results and discussion}

\subsection{Friction behaviour}

Figure 5 shows the effect of burnishing force on coefficient of friction under parallel and crossed burnished orientations ( $\mathrm{PB}-\mathrm{O}$ and $\mathrm{CB}-\mathrm{O})$. In the case of dry sliding condition for $\mathrm{PB}-\mathrm{O}$ (figure 5a), the coefficient of friction decreased, i.e. improved with increasing burnishing force reaching up to $26.8 \%$ and $17.7 \%$ reduction at $250 \mathrm{~N}$ for POM-H and PU, respectively and then increased slighty. The curves revealed that low burnishing force corresponded to a less reduction in the coefficient of friction. This may be ascribed to little or incomplete deformation action of the asperities caused by insufficient compressive action at low burnishing force leading to some asperities being partly deformed and appeared serrated. As a result, higher degree of mechanical interlocking of asperities occurs during sliding. It can also be clearly seen that interposing lubricant at the sliding interface reduces the coefficient of friction for both polymers. This decrease is associated with the separation at interface by boundary lubricant film leading to lower temperature and smoother sliding action. A similar trend was observed for both polymers when sliding test was conducted under $\mathrm{CB}-\mathrm{O}$ (figure $5 \mathrm{~b}$ ). While a decrease in coefficient of friction was achieved in all burnishing force conditions, the lowest value was again achieved at burnishing force of $250 \mathrm{~N}$ corresponding to 21.7 and $19.8 \%$ improvement for POM-H and PU, respectively.

Figure 6 presents the influence of burnishing speed on coefficient of friction under parallel and crossed burnished orientations. The results for $\mathrm{PB}-\mathrm{O}$ under dry sliding condition (figure $6 \mathrm{a}$ ) revealed that less reduction in coefficient of friction was attained at lower burnishing speed $(110 \mathrm{rpm})$ for both polymers, i.e. a mere $3.7 \%$ 

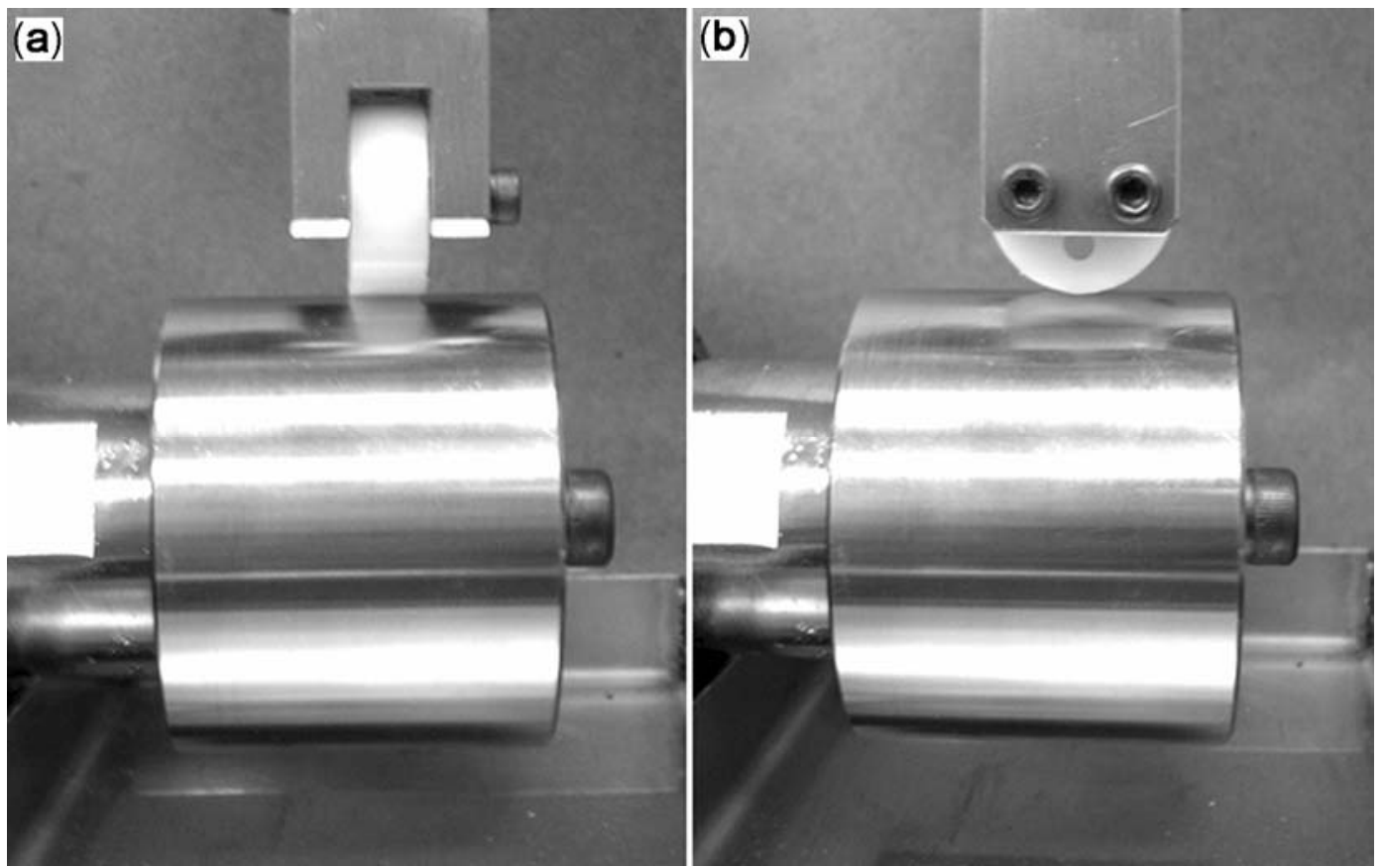

Figure 3. Tribo-test operations: (a) $\mathrm{CB}-\mathrm{O}$, cross burnished orientation and (b) $\mathrm{PB}-\mathrm{O}$, parallel burnished orientation.

and $1.8 \%$ decrease for POM-H and PU, respectively. This may be due to the ploughing and micro-cutting action of the rough asperities present at the polymer surfaces, which in turn elevated the friction. However, as the burnishing speed increased, the coefficient of friction decreased up to $26 \cdot 8 \%(\mathrm{POM}-\mathrm{H})$ and $17.7 \%$ (PU) at a burnishing speed of $330 \mathrm{rpm}$, beyond which it began to increase, indicating that greater deforming action and regular plastic flow due to burnishing took place. Burnishing at higher speed (490 rpm) still decreased the coefficient of friction, albeit at a lesser degree. This phenomena can be explained by the combined effects of two factors. In the first aspect, it has been reported that burnishing requires sufficient lubrication at the interface in order to improve the surface quality (Luo et al 2001), because sliding between two interface results in heat generation at asperities and hence an increase in temperature at the frictional surfaces. In this regard, it may be suggested that the reduced lubrication effect at the burnishing zone at high speed caused a rise in temperature, and as it continues to reach the softening limit of the polymeric materials, the adhesive component began to feature more prominently leading to higher coefficient of friction. In the second aspect, it is well known that the intensity of tool chattering increased at higher speed due to vibration (El-Axir and Ibrahim 2005). This local chattering not only restrained the deforming action of the burnishing roller but also may induce delamination and fracture of the surfaces. Similar explanation can be made for $\mathrm{CB}-\mathrm{O}$ (figure 6b) since it exhibits similar trend. The coefficient of friction in the case of lubricated condition for both orientations remained almost constant within the range studied, however, it can be seen that at all burnishing speed, a reduction in coefficient of friction was achieved.

\subsection{Wear behaviour}

Figure 7 shows the effect of burnishing force on specific wear rate under parallel and crossed burnished orientations. For PB-O under dry sliding conditon (figure 7a), wear decreased as higher burnishing force was applied, gaining as much as 25 and $27.8 \%$ improvement for POM$\mathrm{H}$ and PU, respectively at $250 \mathrm{~N}$. This may be explained by the decreasing trend exhibited by the coeffiction of friction results at higher burnishing force values, where smoother surface with less asperities corresponds to less removal of material during sliding test. In addition, an increase in wear resistance also indicates that the work hardening effect due to higher burnishing force is more pronounced. Moreover, it may be suggested that the resulting surface texture due to roller burnishing increases the compressive residual stress at the surface layers, thus hindering the growth of cracks and wear delamination. On the other hand, low burnishing force, $60 \mathrm{~N}$, tends to result in $9 \%$ degradation of the wear resistance of PU, probably because the insufficient pressure failed to reach the limit of thermosetting polymers like PU, giving rise to incomplete deformation action. Since the wear process in amorphous and brittle like materials such as PU is closely linked to fracture of asperities that takes place during friction process, the high wear rate of PU may be due to the high coefficient of friction values when high 
burnishing force was applied (figure 5a). Accordingly, these fractured particles may further result in resharpening of the particle edges leading to higher wear rate as well which is evident from the SEM micrographs of the worn surfaces shown in figure 8 . The examination of worn surface burnished at $60 \mathrm{~N}$ revealed that a portion of rolled loose debris that accumulated on to the PU surface (figure 8a) acts as an abrasive third body to further abrade the surfaces causing groove marks, as compared to the surface burnished at $250 \mathrm{~N}$, with the latter exhibiting a smoother surface consisting of superficial grooving marks as produced during sliding (figure $8 \mathrm{~b}$ ). However, when a layer of fluid or lubricant is introduced between the sliding surfaces, adhesion junction can hardly be formed due to attenuation of the van der Waals forces. As a result, adhesive wear would be significantly surpressed. Hence, for lubricated contact conditions, there is an almost negligible decreasing trend in wear rate for both polymers with increasing burnishing force although improvements
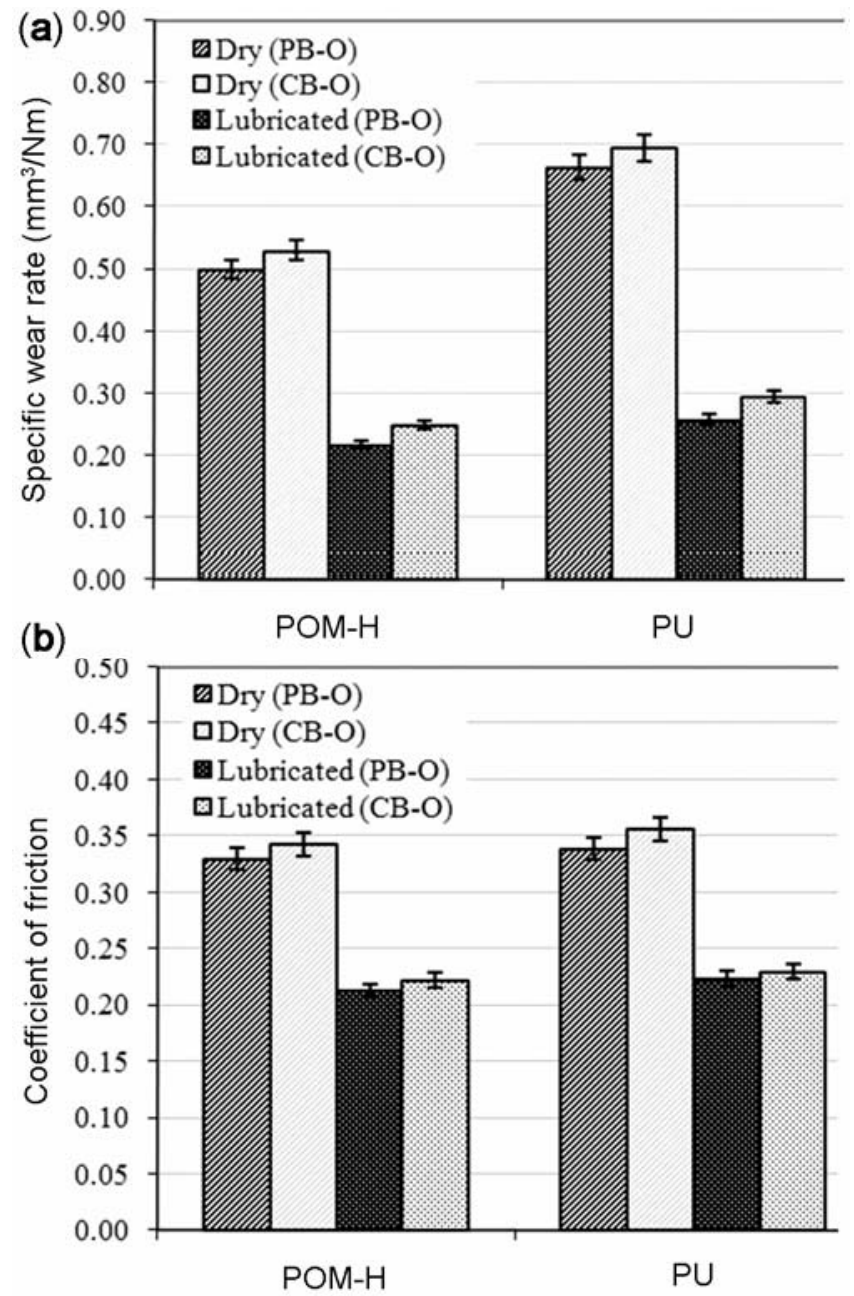

Figure 4. Bar charts showing results of friction and wear tests for turned surfaces: (a) coefficient of friction and (b) specific wear rate. in wear resistance were achieved within the force ranges studied. This indicates that lubrication seems to stabilize the wear rate of burnished surfaces regardless of the
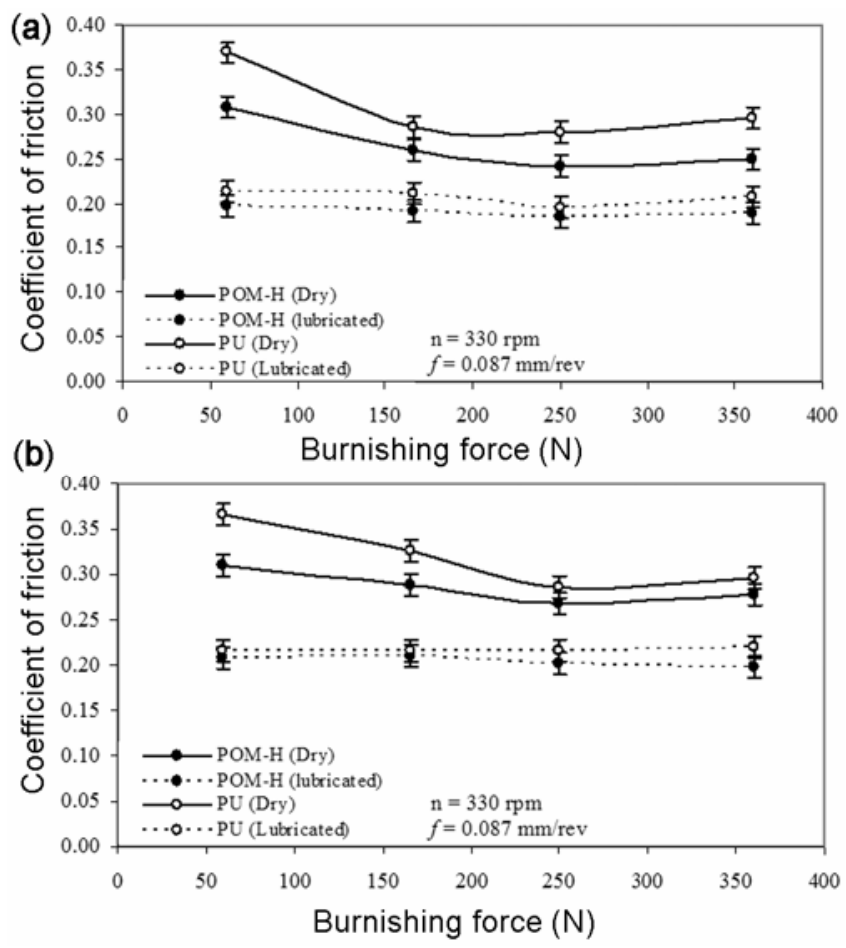

Figure 5. Effect of burnishing force on coefficient of friction: (a) $\mathrm{PB}-\mathrm{O}$ and (b) $\mathrm{CB}-\mathrm{O}$.
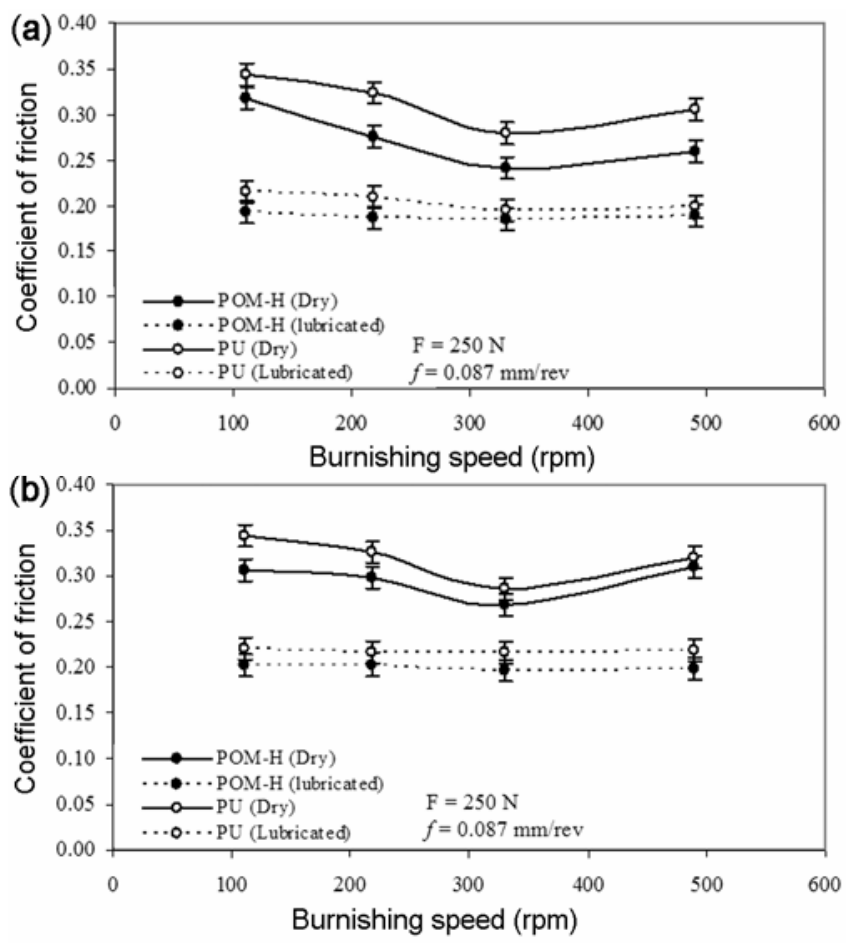

Figure 6. Effect of burnishing speed on coefficient of friction: (a) $\mathrm{PB}-\mathrm{O}$ and (b) $\mathrm{CB}-\mathrm{O}$. 

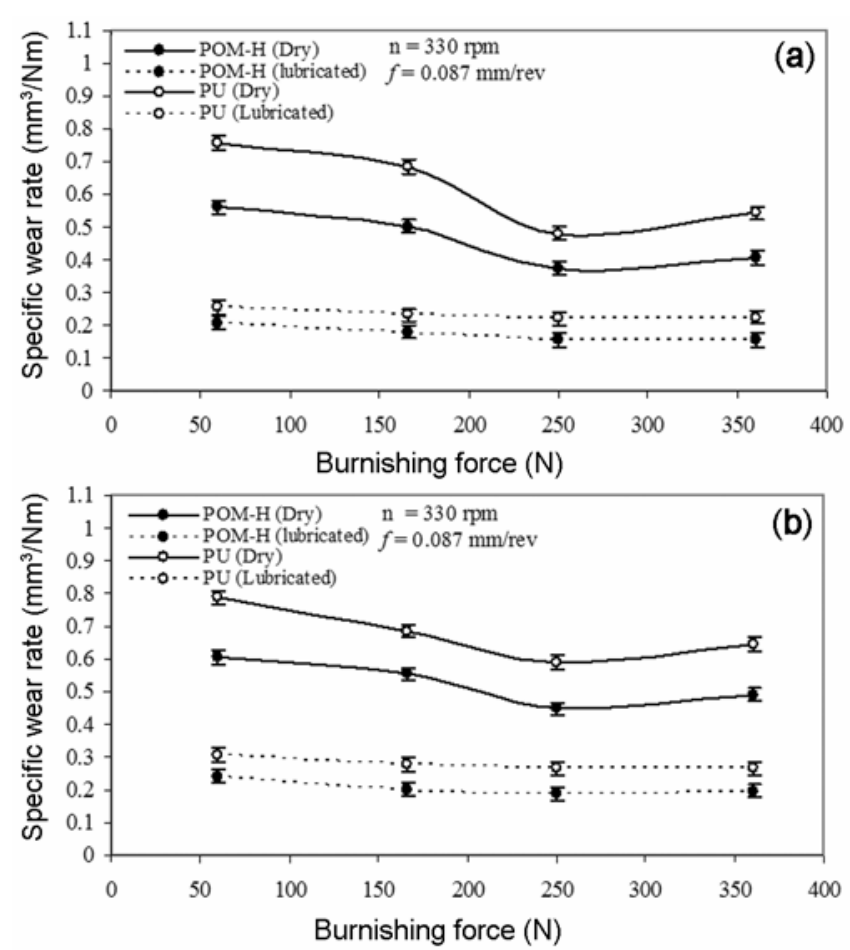

Figure 7. Effect of burnishing force on wear rate: (a) $\mathrm{PB}-\mathrm{O}$ and (b) $\mathrm{CB}-\mathrm{O}$.
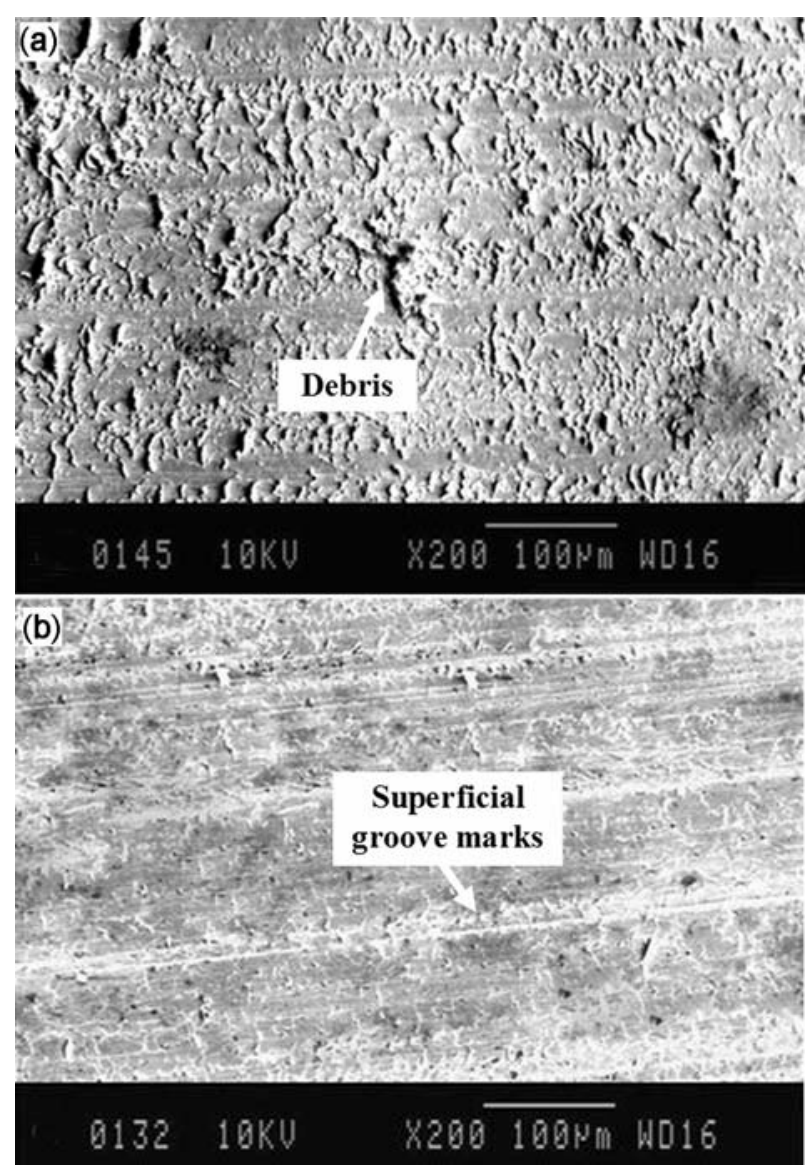

Figure 8. SEM photographs showing feature of worn PU surface under dry sliding $\mathrm{PB}-\mathrm{O}$ condition: surface burnished (a) at $60 \mathrm{~N}$ and (b) $250 \mathrm{~N}$. applied burnishing force. Similar findings were observed in the case of $\mathrm{CB}-\mathrm{O}$ (figure 7b).

Figure 9 presents the effect of burnishing speed on specific wear rate under parallel and crossed burnished orientations. In the case of dry sliding condition for both $\mathrm{PB}-\mathrm{O}$ and $\mathrm{CB}-\mathrm{O}$ conditions, increasing the burnishing speed up to about $330 \mathrm{rpm}$ tends to enhance the wear resistance of both polymers with POM-H showing lesser wear or surface damage than PU. In some non-ferrous components burnishing (El-Axir and Ibrahim 2005), similar enhancement was explained as greater deformation and regular plastic flow occurs, leading to better work hardening effect. This explanation could be extended to burnishing of polymers given that deformation and plastic flow featured more prominently in polymers. Nevertheless, it has been established in prior discussion that greater frictional heat is generated at high burnishing speed because lubricant loses its effect due to limited time to interpose between the burnishing roller and workpiece surface. This frictional heating promoted a temperature rise in the burnishing zone and subsequently softening of the polymer surfaces. As a result, the wear regime can be severe, as featured in the SEM photograph in figure 10 of the worn surface subjected to high burnishing speed. In the case of dry $\mathrm{PB}-\mathrm{O}$ sliding condition (figure 10a), POM-H material showed a wrinkle with wavy morphology surface and a surface degradation caused by melting which happens due to frictional heat
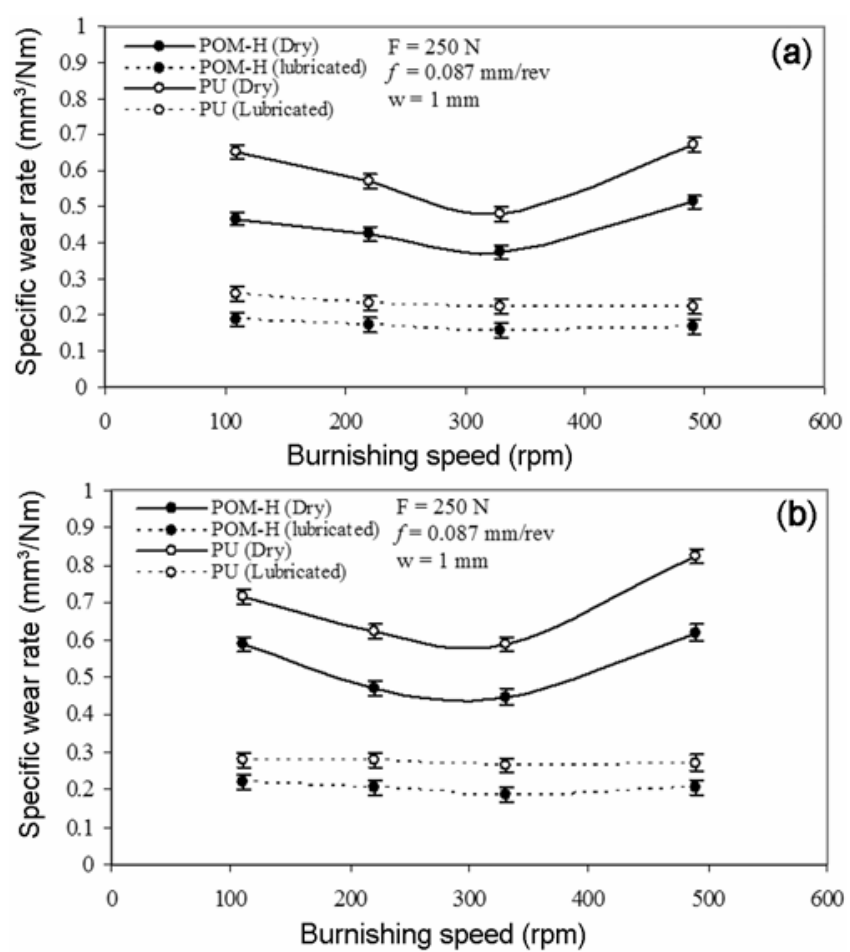

Figure 9. Effect of burnishing speed on wear rate: (a) PB-O and (b) $\mathrm{CB}-\mathrm{O}$. 

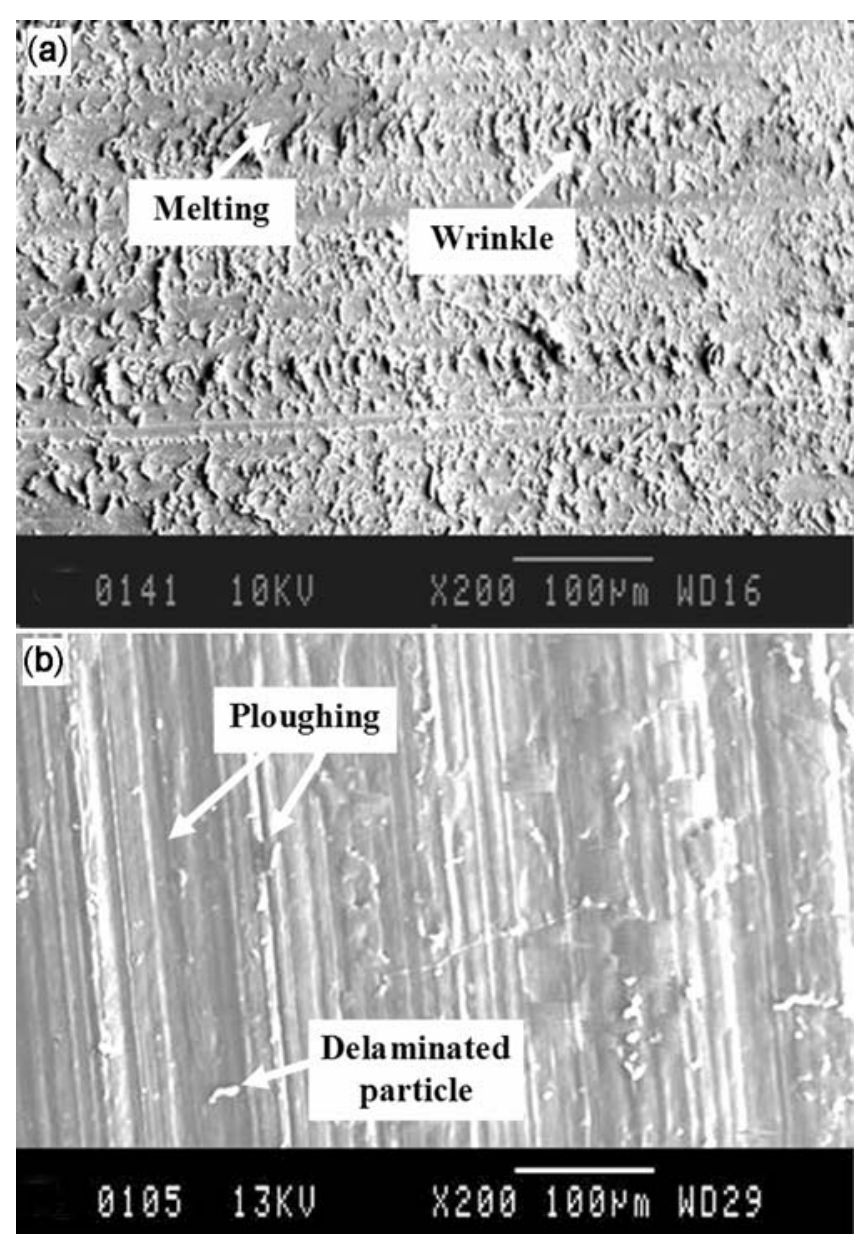

Figure 10. SEM photographs showing feature of worn POM$\mathrm{H}$ surface burnished at $490 \mathrm{rpm}$ under dry sliding condition: (a) $\mathrm{PB}-\mathrm{O}$ and (b) $\mathrm{CB}-\mathrm{O}$.

usually associated at higher speed level. In the case of dry $\mathrm{CB}-\mathrm{O}$ sliding condition, burnishing at high speed appears to offer little protection to the surface from damage. The POM-H worn surface suffered severe shear deformation with wider and deeper grooves caused by the aggressive action of metal asperities of the counterface as observed by surface characterization with SEM (figure 10b). In addition, the surface seems to be covered with thin flakes of delaminated particles which are probably due to local tool chattering effect at high burnishing speed. As a result, the wear regime due to micro-cutting can be radical, as can be affirmed by the results at high burnishing speed. However, such relationship between wear rate and burnishing speed was not displayed for both polymers when the burnished surfaces were tested under lubricated condition, in which the variation of improvement in wear resistance was in the steady state region within the speed range used in this study. Generally, it may be suggested that the low values for the wear rate of $\mathrm{POM}-\mathrm{H}$ as compared to $\mathrm{PU}$ was due to the existence of the transfer film on the POM$\mathrm{H}$ surface.

\section{Conclusions}

The results indicate that roller burnishing is capable of enhancing the tribological properties of both polymers considered in this work. The coefficients of friction of the burnished surfaces were reduced up to 26.8 and $17.7 \%$ for POM-H and PU, respectively. At the same time, the wear rate decreased as much as 25 and $27.8 \%$ POM-H and PU, respectively. However, very high burnishing force and burnishing speed tend to result in degradation of surface quality.

\section{Acknowledgements}

Thanks are due to Dr Nabil, Multimedia University, Malaysia, Dr Brevern, Multimedia University, Malaysia and Dr Belal, University of Southern Queensland, Australia, for their useful comments.

\section{References}

Alauddin M, Choudhury I A, El-Baradi M A and Hashmi M S J 1995 J. Mater. Process. Technol. 5240

Caiazzo F, Canonico P, Nigro R and Tagliaferri V 1996 J. Mater. Process. Technol. $\mathbf{5 8} 96$

Dong H and Bell T 1999 J. Surf. Coat. \& Technol. 11129

El-Axir M H and El-Khabeery M M 2003 J. Mater. Process. Technol. 13282

El-Axir M H and Ibrahim A A 2005 J. Mater. Process. Technol. 16747

El-Tayeb N S M, Low K O and Brevern P V 2008 J. Eng. Tribol. 222947

Hassan A M and Al-Bsharat A S 1996 J. Mater. Process. Technol. 59250

Hassan A M and Al-Bsharat A S 1996 Wear 1991

Hu N S and Zhang L C 2004 J. Mater. Process Technol. 152 333

Luo H, Wang W and Zhang C 2001 J. Mater. Process. Technol. 11688

Prevéy P S and Cammett J T 2004 Int. J. Fatigue 26975

Zhuang W Z and Halford G R 2001 Int. J. Fatigue 2331 